\title{
The Physics Controlling the Sensitivity of Semiconductor Lasers to High Temperatures
}

\author{
A. R. Adams and S. J. Sweeney \\ Advanced Technology Institute, University of Surrey, Guildford, Surrey, GU2 7XH, UK
}

The temperature dependence of the gain and loss processes in uncooled $1.3 \mu \mathrm{m}$ and $1.55 \mu \mathrm{m}$ quantum-well and quantum-dot lasers are discussed and the performance of various materials combinations and structures are compared and contrasted.

\begin{abstract}
Temperature stable, cheap, semiconductor lasers working in the wavelength range from about $1.3 \mu \mathrm{m}$ to 1.6 $\mu \mathrm{m}$ would be ideal light sources for optical fibre communications. Unfortunately their threshold current density, $\mathrm{J}_{\text {th }}$, tends to increase quickly and their quantum differential efficiency decreases above room temperature (RT). Here we discuss the fundamental causes of this behaviour and its possible reduction by improved device structure and materials combinations.
\end{abstract}

We can characterize the rate of increase of $\mathrm{J}_{\text {th }}$ at any temperature by $\mathrm{d}\left(\ln \mathrm{J}_{\mathrm{th}}\right) / \mathrm{dT}=1 / \mathrm{T}_{0}$ (1). Thus $\mathrm{J}_{\text {th }}$ would increase by a factor " $\mathrm{e}$ " over the temperature interval $\mathrm{T}_{0}$. A simple model for an ideal quantumwell laser predicts that the threshold current density due to radiative transitions alone may be written as $\mathrm{J}_{\text {rad }}=\mathrm{Bn}_{\mathrm{th}}{ }^{2}$ where $\mathrm{B}=\mathrm{B}_{0} / \mathrm{T}$ and the carrier concentration at threshold $\mathrm{n}_{\mathrm{th}}=\mathrm{n}_{0} \mathrm{~T}$. Hence $\mathrm{J}_{\mathrm{rad}} \propto \mathrm{T}$ and $\mathrm{T}_{0}=\mathrm{T}$ [1]. Thus we would expect $\mathrm{T}_{0}$ to be about $300 \mathrm{~K}$ at $\mathrm{RT}$ and to increase at higher temperatures. Studies of $\mathrm{J}_{\mathrm{rad}}$ in $1.3 \mu \mathrm{m}$ and $1.55 \mu \mathrm{m}$ GaInAsP/InP compressively strained quantum well lasers show this holds remarkably well, probably because the distribution of holes in the valence band remains non-degenerate. Fig. 1 shows the measured variation of the integrated light intensity, L, collected from a small window milled in the substrate electrode of a $1.5 \mu \mathrm{m} \mathrm{GaInAsP/InP}$ laser. At currents above threshold $n_{\text {th }}$ is kept pinned by the lasing process resulting in a constant value of $\mathrm{L}=\mathrm{L}_{\text {th }}$ which is proportional to $\mathrm{J}_{\text {rad }}$.

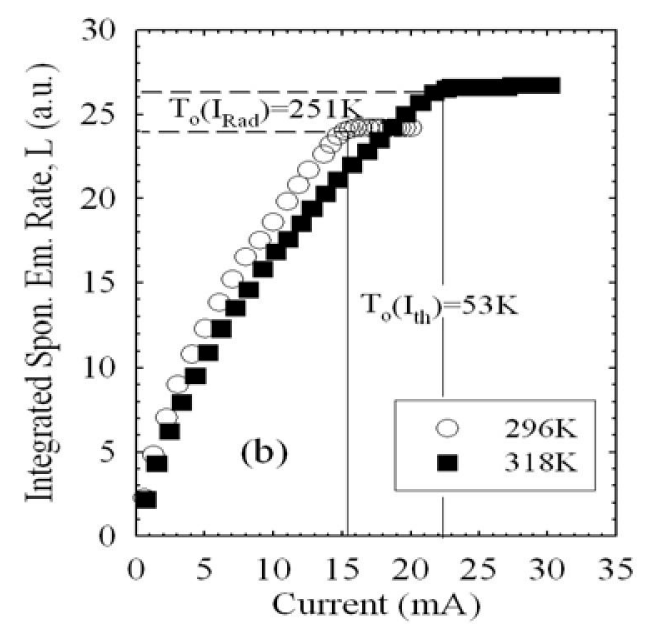

Figure I Determination of $T_{o}$ and $T_{o}\left(J_{\text {rad }}\right)$ for a $1.5 \mu$ m laser.

$\mathrm{L}_{\text {th }}$ does indeed have a characteristic temperature $\mathrm{T}_{0}\left(\mathrm{~J}_{\mathrm{rad}}\right) \approx \mathrm{T}$, however the variation of $\mathbf{J}_{\mathrm{th}}$, indicated by the vertical lines is closer to a $\mathrm{T}_{0}\left(\mathrm{~J}_{\mathrm{th}}\right)=\mathrm{T} / 5$ indicating an additional strongly temperature sensitive non-radiative recombination process.

Fig 2 shows that at low temperatures $\mathrm{J}_{\text {th }}$ for a $1.3 \mu \mathrm{m}$ and $1.5 \mu \mathrm{m}$ lasers behaves ideally and increases linearly. For clarity $\mathbf{J}_{\mathrm{th}}$ for the devices is shown normalised at low temperatures, although high pressure measurements have shown that $\mathrm{J}_{\text {th }} \propto \mathrm{E}_{\mathrm{g}}{ }^{2}$ so $\mathrm{J}_{\text {th }}$ for the $1.5 \mu \mathrm{m}$ device is actually lowest at low temperature. The dashed curve is normalised variation of $\mathrm{J}_{\text {rad. }} \mathrm{J}_{\text {th }}$ for the $1.5 \mu \mathrm{m}$ device starts to increase super-linearly at about $150 \mathrm{~K}$ and $\mathrm{J}_{\text {th }}$ is about $5 \mathrm{xJ}_{\mathrm{rad}}$ at $300 \mathrm{~K}$ indicating that nonradiative recombination constitutes about $80 \%$ of $\mathrm{J}_{\text {th }}$ near RT. For the $1.3 \mu \mathrm{m}$ device the corresponding values are $200 \mathrm{~K}$ with $\mathrm{J}_{\text {th }}$ about 


\section{OThN1.pdf}

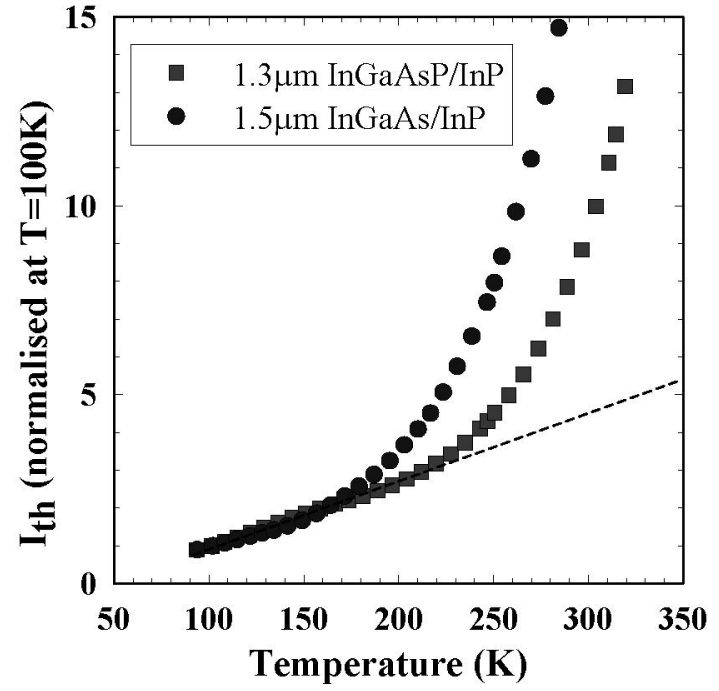

Figure 2 Temperature dependence of $J_{\text {th }}$ for a $1.3 \mu \mathrm{m}$ and 1.5 um laser together with $J_{\text {rad }}$ (dashed line).

$2 \mathrm{xJ}_{\mathrm{rad}}$ at $300 \mathrm{~K}$. Thus the non-radiative recombination process decreases swiftly with increasing $\mathrm{E}_{\mathrm{g}}$. Also, writing $\mathrm{J} \sim \mathrm{n}^{\mathrm{z}}$, since $\mathrm{L}=\mathrm{Bn}^{2}$, a plot of $\ln (\mathrm{J})$ vs $\ln \left(\mathrm{L}^{1 / 2}\right)$ has a gradient of $Z$. Figure 3, shows that the measured values of $Z$ at threshold are close to 2 at low temperatures but increase to $Z \approx 3$ where the non-radiative transitions dominate, indicating the presence of Auger recombination which involves three carriers and results in a current $\mathrm{J}_{\mathrm{Aug}}=\mathrm{Cn}^{3}$.

If Auger recombination dominates we may write $\mathrm{J}_{\mathrm{th}}=\mathrm{Cn}_{\mathrm{th}}{ }^{3}=\mathrm{C}\left(\mathrm{n}_{0} \mathrm{~T}\right)^{3}$ and equation (1)

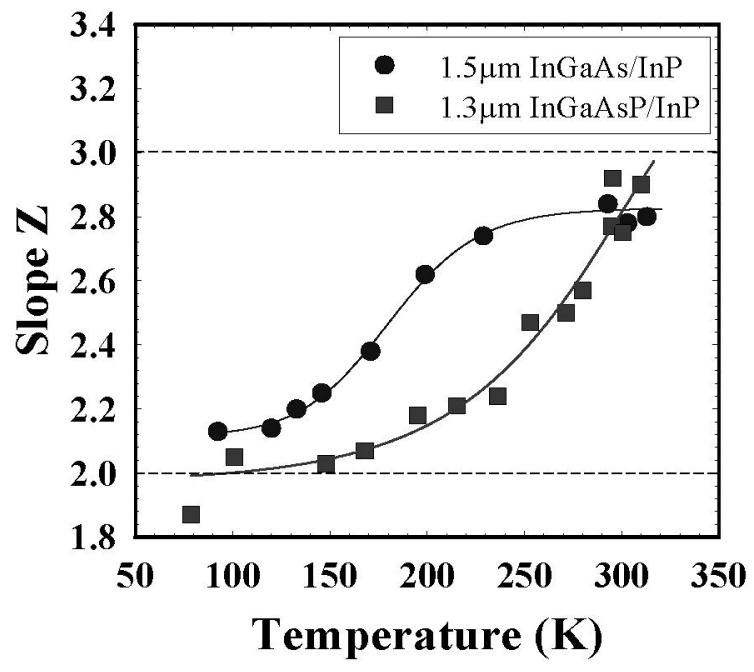

Figure 3 Temperature dependence of Z-parameter for a $1.3 \mu \mathrm{m}$ and $1.5 \mu \mathrm{m}$ laser. yields $\mathrm{T}_{0}=\mathrm{T} / 3$ or $\mathrm{T}_{0} \approx 100 \mathrm{~K}$ at $\mathrm{RT}$. If the Auger process has a thermal activation energy $E_{a}$ then $T_{0}$ is reduced further to $\mathrm{T}_{0}=\mathrm{T} /\left(3+\mathrm{E}_{\mathrm{a}} / \mathrm{kT}\right)$ so this and/or a degree of inter-valence band absorption would explain very well the measured value of $\mathrm{T}_{0}$. More evidence is obtained from the decrease of $\mathrm{J}_{\text {th }}$ [1] with increasing hydrostatic pressure shown in Figure 4. This is fit best by assuming a CHSH Auger process, which involves the excitation of a hot hole and so $\mathrm{J}_{\mathrm{Aug}}=\mathrm{Cn}_{\mathrm{th}} \mathrm{p}_{\mathrm{th}}{ }^{2}$.

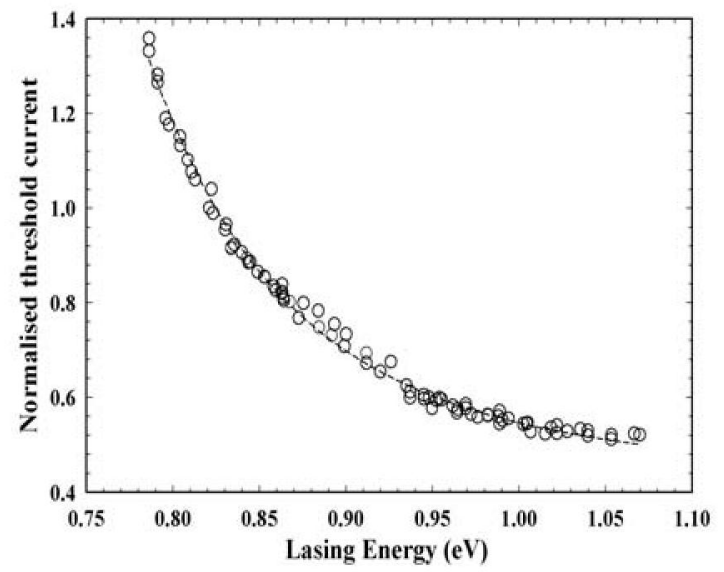

Figure 4 Photon energy dependence of $J_{\text {th }}$ over the wavelength range 1.3-1.6 $\mathrm{\mu m}$ showing the characteristic decrease associated with Auger recombination.

Armed with this information the following steps may be taken to reduce $J_{\text {th }}$ and its temperature sensitivity.

(1) Since $\mathrm{J}_{\text {Aug }}=\mathrm{Cn}_{\mathrm{th}}{ }^{3}$ and $\mathrm{J}_{\mathrm{rad}}=\mathrm{Bn}_{\mathrm{th}}{ }^{2}$ it is clearly advantageous to reduce $n_{\text {th }}$. Previous work has shown the influence on $\mathrm{J}_{\text {th }}$ of varying the number of wells in GaInAsP lasers at RT [2]. The number at which $\mathbf{J}_{\mathrm{th}}$ is a minimum will increase with increasing temperature and so can be chosen for the temperature range of importance.

2) Introduce compressive or tensile strain in the wells as discussed in detail elsewhere [3].

3) Change the relative conduction and valence band offsets. Figure 6 shows qualitatively the band alignment of single InGaAsP/InP, InGaAlAs/InP and InGaAsN/GaAs quantum wells before current 


\section{OThN1.pdf}

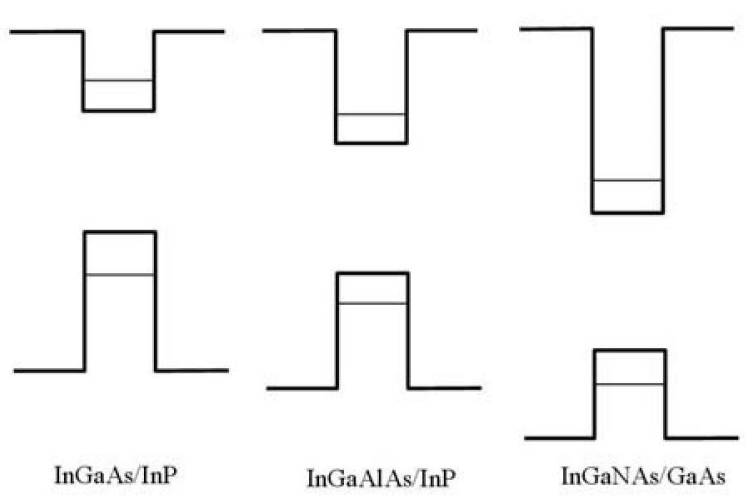

Figure 5 Schematic band alignments (at zero bias) for InGaAs/InP, InGaAlAs/InP and InGaNAs/GaAs 1.3 um lasers.

injection. The faster thermal excitation of the carrier type with the smallest confinement will cause the build up of an electrostatic field until the rate of escape of electrons and holes are equal and governed by the sum of the confinement energies. This tends to increase the radiative current density but may decrease the Auger current of the form $\mathbf{J}_{\mathrm{Aug}}=$ $\mathrm{Cn}_{\mathrm{th}} \mathrm{p}_{\mathrm{th}}{ }^{2}$. In GaInAsP/InP $\mathrm{n}_{\mathrm{th}}<\mathrm{p}_{\mathrm{th}}$ and $\mathrm{J}_{\text {Aug }}$ is increased. In GaAlInAs/InP $n_{\text {th }}$ remains $=p_{\text {th }}$ and $\mathrm{J}_{\text {Aug }}$ remains unaltered. This explains the observed lower temperature sensitivity of InGaAlAs/InP devices compared with InGaAs(P)/InP devices, as shown in Figure 6 for lasers emitting at $1.5 \mu \mathrm{m}$.

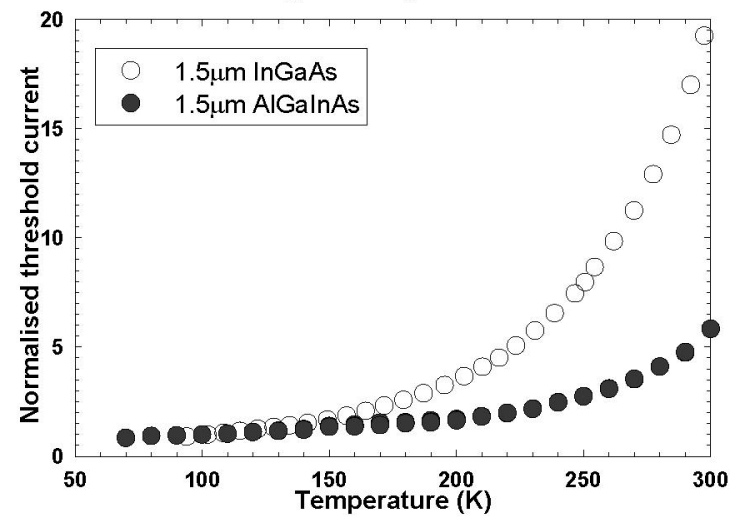

Figure 6 Temperature dependence of $J_{\text {th }}$ for a $1.5 \mu \mathrm{m}$ In GaAs and InGaAlAs laser.

In GaInAsN/GaAs $n_{\text {th }}>p_{\text {th }}$ and $J_{\text {Aug }}$ and $J_{\text {th }}$ is expected to be reduced. Unfortunately, in the GaInAsN/GaAs material presently available, $\mathrm{J}_{\text {th }}$ in is dominated by recombination through defects [4] and its full potential has not been demonstrated.

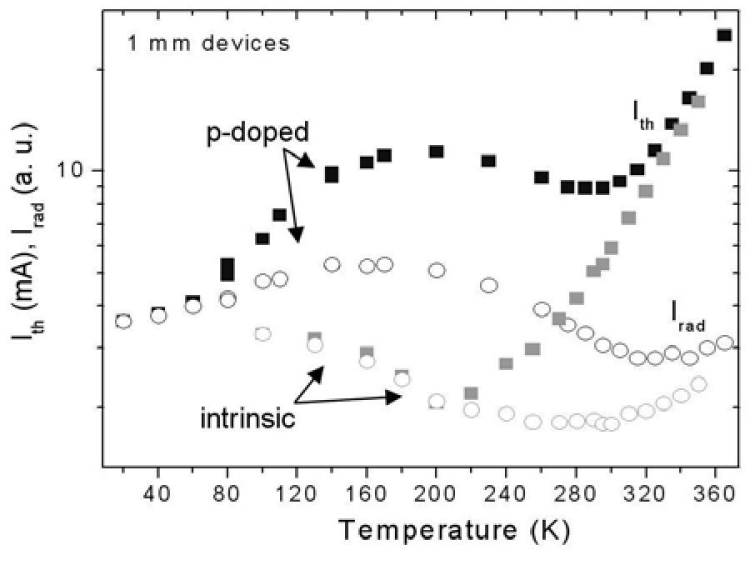

Figure 7 Temperature dependence of $J_{\text {th }}$ and $J_{\text {rad }}$ for intrinsic and p-doped 1.3 $\mu \mathrm{m}$ QDot lasers.

There has been considerable effort to produce $1.3 \mu \mathrm{m}$ lasers with superior threshold characteristics based on the $3 \mathrm{D}$ quantum confinement provided by semiconductor quantum dots (QDs). The radiative and nonradiative components of the threshold current in $1.3 \mu \mathrm{m}, \mathrm{p}$-doped and undoped quantum-dot semiconductor lasers were studied between $20 \mathrm{~K}$ and $370 \mathrm{~K}$ (Figure 7) [5]. The complex behaviour can be explained simply assuming that the radiative recombination and nonradiative Auger recombination rates are strongly modified by thermal redistribution of carriers between the dots. The large differences between the devices arise due to the trapped holes in the p-doped devices. These both greatly increase Auger recombination involving hole excitation at low temperatures and decrease electron thermal escape due to their Coulombic attraction. The model explains the high $\mathrm{T}_{0}$ values observed near room temperature and shows that by increasing the p-doping an almost infinite $\mathrm{T}_{0}$ can be achieved over a selected temperature range, but at the expense of an increased $\mathbf{J}_{\mathrm{th}}$ and a decreased quantum differential efficiency.

\section{References}

[1] A. F. Philips et al IEEE JSTQE, 5, 401 (1999)

[2] M. Silver and E. P. O'Reilly, IEEE JQE, 31, 1193 (1995).

[3] A. R. Adams, Elec. Lett., 22, 249 (1986).

[4] R. Fehse et al, IEEE JSTQE, 8, 801 (2002).

[5] I. P. Marko et al, APL, to be published (2005). 